\title{
Perbandingan persalinan seksio sesarea dan pervaginam pada wanita hamil dengan obesitas
}

\author{
${ }^{1}$ Adelia S. Ekwendi \\ ${ }^{2}$ Maya E. Mewengkang \\ ${ }^{2}$ Frank M. M. Wagey
}

\author{
${ }^{1}$ Kandidat Skripsi Fakultas Kedokteran Universitas Sam Ratulangi Manado \\ ${ }^{2}$ Bagian Obstetri dan Ginekologi Fakultas Kedokteran Universitas Sam Ratulangi Manado \\ RSUP Prof. Dr. R. D. Kandou Manado \\ Email: adeliaekwendi12224@gmail.com
}

\begin{abstract}
Obesity is a problem throughout the world and is commonly found among women in the region of Southeast Asia. Obesity in pregnant women increases the risk of complications associated with an increasing incidence of caesarean section and a decreasing incidence of vaginal delivery. This study aimed to determine the comparison of caesarean section and vaginal delivery in pregnant women with obesity. This was a descriptive study with a cross-sectional approach. This study used data of the patients' medical record. Samples were all pregnant women with obesity $\left(B M I \geq 30 \mathrm{~kg} / \mathrm{m}^{2}\right.$ ) at the end of pregnancy who underwent caesarean sections and vaginal deliveries in Prof. Dr. R. D. Kandou Hospital Manado from January 2014 until October 2015. The data were processed by using the Microsoft Excel. The results showed that the number of pregnant women with obesity was 926 and of pregnant women who underwent caesarean section was 50.22\%. Pregnant women with obesity in the age group over 30 years, nutritional status obese II and III, and body weight over $85 \mathrm{~kg}$ were more frequent in undergoing the cesarean section. Conclusion: The higher BMI, body weight, and age of a pregnant woman, the higher risk of undergoing cesarean section compared to vaginal delivery.
\end{abstract}

Keywords: BMI, obesity, caesarean section, vaginal delivery

\begin{abstract}
Abstrak: Obesitas merupakan masalah yang mendunia dan paling banyak dialami oleh wanita di wilayah Asia-Tenggara. Obesitas pada wanita hamil meningkatkan risiko terjadinya komplikasi yang berhubungan dengan peningkatan angka kejadian persalinan seksio sesarea dan penurunan kejadian persalinan pervaginam. Penelitian ini bertujuan untuk mengetahui perbandingan persalinan seksio sesarea dan pervaginam pada wanita hamil dengan obesitas. Penelitian ini menggunakan metode deskriptif dengan pendekatan potong lintang. Penelitian dilakukan dengan melihat catatan rekam medis pasien. Sampel penelitian ialah seluruh wanita hamil dengan obesitas (IMT $\geq 30 \mathrm{~kg} / \mathrm{m}^{2}$ ) pada akhir kehamilan yang menjalani persalinan seksio sesarea dan pervaginam di RSUP Prof. Dr. R. D. Kandou Manado dari bulan Januari 2014 sampai Oktober 2015. Data yang diperoleh diolah dengan menggunakan Microsoft excel. Hasil penelitian menunjukkan bahwa jumlah wanita hamil dengan obesitas 926 orang dan yang menjalani seksio sesarea sebanyak 50,22\%. Wanita hamil dengan obesitas pada kelompok umur di atas 30 tahun, status gizi obes II dan III, serta kelompok berat badan lebih dari 85 kg lebih banyak menjalani persalinan seksio sesarea. Simpulan: Semakin meningkat IMT, berat badan, dan usia seorang wanita hamil, maka semakin tinggi risiko menjalani persalinan seksio sesarea dibandingkan pervaginam.
\end{abstract}

Kata kunci: IMT, obesitas, seksio sesarea, persalinan pervaginam 
Obesitas merupakan masalah yang mendunia selama satu dekade terakhir dan menjadi risiko terbesar kelima yang dapat menyebabkan kematian secara global. Setiap tahun, sekitar 2,8 juta orang dewasa meninggal karena obesitas dan overweight. Berdasarkan data dari WHO, pada tahun 2014, lebih dari 1,9 milyar orang usia lebih dari 18 tahun mengalami overweight dan 600 juta diantaranya merupakan obes. $^{1}$ Survey dari National Health and Nutrition Examination di Amerika, lebih dari sepertiga wanita mengalami obesitas, lebih dari setengah wanita hamil mengalami overweight dan obesitas, dan 8\% wanita pada usia reproduktif mengalami obesitas. ${ }^{2}$ Di semua wilayah di Asia-Tenggara, obesitas paling banyak dialami oleh wanita dibandingkan oleh pria. ${ }^{1}$ Menurut data RISKESDAS pada tahun 2013, prevalensi obesitas tertinggi pada wanita Indonesia terdapat di Sulawesi Utara dengan persentase $19,5 \% .^{3}$

Obesitas pada wanita merupakan faktor risiko masalah obstetri ginekologi karena dapat mempengaruhi fungsi reproduksi dalam berbagai aspek. ${ }^{4}$ Salah satu masalah reproduksi yang dapat terjadi pada wanita dengan obesitas adalah masalah pada kehamilan. ${ }^{4,5}$ Obesitas pada wanita hamil meningkatkan risiko terjadinya komplikasi yang berhubungan dengan peningkatan angka kejadian persalinan seksio sesarea., ${ }^{6,7}$ Komplikasi yang dapat terjadi berupa diabetes gestasional, hipertensi, preeklampsi, makrosomia, dan persalinan preterm. ${ }^{2,8,9}$

Pada awalnya, persalinan pervaginam merupakan persalinan yang paling banyak diketahui oleh masyarakat. Seiring perkembangan teknologi dan berbagai komplikasi dalam kehamilan kejadian persalinan seksio sesarea semakin meningkat dan persalinan pervaginam semakin berkurang. ${ }^{10}$ Sejak tahun 1985, WHO menyarankan jumlah persalinan seksio sesarea tidak melebihi $10-15 \%$ dari seluruh jumlah persalinan. ${ }^{11,12}$ Namun, angka kejadian persalinan seksio sesarea semakin meningkat selama satu dekade terakhir yang menjadikan hal ini sebagai masalah kesehatan di dunia. ${ }^{11}$

Persalinan seksio sesarea menyebabkan peningkatan morbiditas dan mortalitas bagi wanita hamil. ${ }^{7,13}$ Wanita yang menjalani persalinan seksio sesarea harus tinggal di rumah sakit lebih lama dan bayinya lebih banyak di rawat di neonatal intensive care dibandingkan dengan wanita yang menjalani persalinan pervaginam. ${ }^{13}$

Hasil penelitian yang dilakukan oleh $\mathrm{Al}-$ Kubaisy $\mathrm{W}$ et al. menunjukkan terdapat hubungan yang signifikan antara indeks massa tubuh dengan risiko persalinan seksio sesarea. ${ }^{6}$ Studi metaanalisis-kohort yang dilakukan oleh Poobalan et al. menunjukkan bahwa risiko persalinan seksio sesarea meningkat $50 \%$ pada wanita dengan IMT 30-35 kg/m² dan angkanya menjadi dua kali lipat pada wanita dengan IMT $>35 \mathrm{~kg} / \mathrm{m}^{2}$ dibandingkan dengan wanita yang memiliki IMT $20-25 \mathrm{~kg} / \mathrm{m}^{2}{ }^{14}$ Penelitian yang serupa juga dilakukan oleh Liu et al. yang menyatakan bahwa dibandingkan dengan yang memiliki berat badan normal, wanita overweight atau obes memiliki kejadian lebih tinggi untuk menjalani persalinan seksio sesarea. ${ }^{15}$

Beberapa penelitian juga mengemukakan bahwa terjadi peningkatan risiko morbiditas dan mortalitas pada wanita obes yang menjalani persalinan seksio sesarea. ${ }^{7}$ Persalinan seksio sesarea pada wanita obes juga berkaitan dengan lamanya waktu operasi, lamanya tinggal di rumah sakit, kehilangan darah saat operasi, infeksi postoperatif, jumlah penggunaan anestesi dan besarnya biaya operasi. ${ }^{7,16}$

Penelitian ini bertujuan untuk mengetahui perbandingan persalinan seksio sesarea dan pervaginam pada wanita obes.

\section{METODE PENELITIAN}

Penelitian ini menggunakan metode deskriptif dengan pendekatan potong lintang. Penelitian ini dilakukan di RSUP Prof. Dr. R.D. Kandou Manado pada bulan November 2015 sampai Desember 2015 dengan melihat catatan rekam medis pasien. 
Sampel penelitian ini ialah seluruh wanita dengan obesitas pada akhir kehamilan yang menjalani persalinan seksio sesarea dan pervaginam di RSUP Prof. Dr. R. D. Kandou Manado dari bulan Januari 2014 sampai Oktober 2015. Kriteria eksklusi dalam penelitian ini adalah ibu hamil dengan plasenta previa, panggul sempit kurang dari 8,5 cm, letak janin lintang, dan gemeli.

Wanita hamil dengan obesitas didefinisikan sebagai ibu hamil dengan IMT $\geq 30 \mathrm{~kg} / \mathrm{m}^{2}$ pada akhir kehamilan. Persalinan pervaginam didefinisikan sebagai ibu hamil yang menjalani persalinan melalui jalan lahir, baik secara fisiologis tanpa alat bantu maupun dengan alat bantu seperti forceps dan vacum.

Data yang diperoleh diolah menggunakan Microsoft Excel dan disajikan dalam bentuk tabel.

\section{HASIL PENELITIAN}

Pada periode Januari 2014 sampai Oktober 2015 terdapat 4.826 wanita hamil yang melahirkan di RSUP Prof. dr. R. D. Kandou Manado dengan pembagian 3.347 yang melahirkan di tahun 2014 dan 1.479 yang melahirkan di Januari sampai Oktober 2015.

Tabel 1. Perbandingan persalinan seksio sesarea dan pervaginam berdasarkan periode pada wanita hamil dengan obesitas pada akhir kehamilan

\begin{tabular}{|c|c|c|c|c|}
\hline \multirow{2}{*}{ Periode } & \multicolumn{2}{|c|}{$\begin{array}{l}\text { Seksio } \\
\text { Sesarea }\end{array}$} & \multicolumn{2}{|c|}{ Pervaginam } \\
\hline & $\mathrm{n}$ & $\%$ & $\mathrm{n}$ & $\%$ \\
\hline 2014 & 349 & 75,05 & 338 & 73,32 \\
\hline Januari & 116 & 24,95 & 123 & 26,68 \\
\hline Oktober 2015 & & & & \\
\hline Total & 465 & 100 & 461 & 100 \\
\hline
\end{tabular}

Wanita hamil dengan obesitas pada akhir kehamilan dari Januari 2014 sampai Oktober 2015 adalah 926 orang dengan persentase $19,19 \%$ dari seluruh persalinan.
Pada Tabel 2 terlihat bahwa persentase persalinan seksio sesarea dan pervaginam hampir sama. Namun, persalinan seksio sesarea lebih tinggi dengan persentase $50,22 \%$.

Tabel 3 menunjukkan bahwa persalinan paling banyak dilakukan pada kelompok umur 20 sampai 30 tahun. Pada kelompok umur kurang dari 30 tahun paling banyak menjalani persalinan pervaginam dan di atas 30 tahun lebih banyak menjalani persalinan seksio sesarea.

Tabel 2. Perbandingan persalinan seksio sesarea dan pervaginam periode Januari 2014 sampai Oktober 2015 pada wanita hamil dengan obesitas di akhir kehamilan

\begin{tabular}{lcc}
\hline Jenis Persalinan & $\mathrm{n}$ & $\%$ \\
\hline Seksio sesarea & 465 & 50,22 \\
Pervaginam & 461 & 49,78 \\
Total & 926 & 100 \\
\hline
\end{tabular}

Pada Tabel 4 terlihat bahwa obes I merupakan tingkatan obes yang paling banyak dialami oleh wanita hamil dengan obesitas di akhir kehamilan. Pada wanita hamil dengan obes I lebih banyak menjalani persalinan pervaginam dan pada obes II dan III lebih banyak menjalani persalinan seksio sesarea.

Pada Tabel 5 terlihat bahwa persalinan pada wanita hamil dengan kelompok berat badan 60 sampai $85 \mathrm{~kg}$ lebih banyak menjalani persalinan pervaginam sedangkan pada kelompok berat badan lebih dari $85 \mathrm{~kg}$ lebih banyak menjalani persalinan seksio sesarea.

Pada Tabel 6 terlihat bahwa wanita hamil dengan obesitas di akhir kehamilan lebih banyak multipara dibandingkan primipara. Namun, perbedaan antara persalinan seksio sesarea dan pervagiman dari primipara maupun multipara tidak memberikan angka yang mencolok karena jumlah setiap jenis persalinan hampir sama. 
Ekwendi, Mewengkang, Wagey: Perbandingan persalinan seksio...

Tabel 3. Perbandingan setiap jenis persalinan berdasarkan umur pada wanita hamil dengan obesitas di akhir kehamilan

\begin{tabular}{lcccccc}
\hline \multirow{2}{*}{ Umur } & \multicolumn{2}{c}{$<20$ tahun } & \multicolumn{2}{c}{$20-30$ tahun } & \multicolumn{2}{c}{$>30$ tahun } \\
\cline { 2 - 7 } Jenis Persalinam & $\mathrm{n}$ & $\%$ & $\mathrm{n}$ & $\%$ & $\mathrm{n}$ & $\%$ \\
\hline Seksio Sesarea & 23 & 39,66 & 210 & 46,26 & 232 & 56,04 \\
Pervaginam & 35 & 60,34 & 244 & 53,74 & 182 & 43,96 \\
Total & 58 & 100 & 454 & 100 & 414 & 100 \\
\hline
\end{tabular}

Tabel 4. Perbandingan setiap jenis persalinan berdasarkan IMT pada wanita hamil dengan obesitas di akhir kehamilan

\begin{tabular}{lcccccc}
\multicolumn{1}{c}{ IMT } & \multicolumn{2}{c}{$\begin{array}{c}30-34,99 \\
\text { (Obes I) }\end{array}$} & \multicolumn{2}{c}{$\begin{array}{c}35-39,99 \\
\text { (Obes II) }\end{array}$} & \multicolumn{2}{c}{$\begin{array}{c}\text { (Obes III) } \\
\text { Jenis Persalinan }\end{array}$} \\
\cline { 2 - 8 } & $\mathrm{n}$ & $\%$ & $\mathrm{n}$ & $\%$ & $\mathrm{n}$ & $\%$ \\
\hline Seksio Sesarea & 315 & 45,92 & 116 & 60,73 & 34 & 69,39 \\
Pervaginam & 371 & 54,08 & 75 & 39,27 & 15 & 30,61 \\
Total & 686 & 100 & 191 & 100 & 49 & 100 \\
\hline
\end{tabular}

Tabel 5. Perbandingan setiap jenis persalinan berdasarkan berat badan pada akhir kehamilan

\begin{tabular}{lcccccc}
\hline \multirow{2}{*}{ Umur } & \multicolumn{2}{c}{$<60 \mathrm{~kg}$} & \multicolumn{2}{c}{$60-85 \mathrm{~kg}$} & \multicolumn{2}{c}{$>85 \mathrm{~kg}$} \\
\cline { 2 - 7 } Jenis Persalinam & $\mathrm{n}$ & $\%$ & $\mathrm{n}$ & $\%$ & $\mathrm{n}$ & $\%$ \\
\hline Seksio Sesarea & 1 & 50 & 356 & 47,21 & 108 & 63,53 \\
Pervaginam & 1 & 50 & 398 & 52,79 & 62 & 36,47 \\
Total & 2 & 100 & 754 & 100 & 170 & 100 \\
\hline
\end{tabular}

Tabel 6. Perbandingan setiap jenis persalinan berdasarkan jumlah paritas pada wanita hamil dengan obesitas di akhir kehamilan

\begin{tabular}{lcccc} 
Paritas & \multicolumn{2}{c}{ Primipara } & \multicolumn{2}{c}{ Multipara } \\
\cline { 2 - 5 } Persalinan & $\mathrm{n}$ & $\%$ & $\mathrm{n}$ & $\%$ \\
\hline Seksio & 177 & 49,03 & 288 & 50,97 \\
Sesarea & & & & \\
Pervaginam & 184 & 50,97 & 277 & 49,03 \\
Total & 361 & 100 & 565 & 100 \\
\hline
\end{tabular}

\section{BAHASAN}

Obesitas merupakan suatu masalah yang mendunia. Di dunia, obesitas meningkat dua kali lipat selama 30 tahun terakhir dan hal ini juga terjadi pada wanita hamil. Obesitas pada kehamilan menjadi suatu masalah kesehatan karena dapat meningkatkan morbiditas dan mortalitas bagi ibu maupun bayi. ${ }^{17}$

Pada penelitian ini didapatkan bahwa dari 4.826 wanita hamil yang menjalani persalinan terdapat 926 wanita hamil yang memiliki status gizi obes di Prof. Dr. R. D. Kandou Manado selama periode Januari 2014 sampai Oktober 2015 dengan persentase 19,19\%. Hal ini menunjukkan bahwa obesitas pada wanita hamil semakin meningkat khususnya di Manado, mengingat Manado juga merupakan kota dengan prevalensi obesitas tertinggi pada wanita di Indonesia dengan persentase $19,5 \%$.

Obesitas pada wanita hamil dapat menyebabkan berbagai komplikasi dalam kehamilan baik bagi ibu maupun bagi janin. Hal ini disebabkan akibat asupan gizi yang salah sebelum prekonsepsi maupun selama kehamilan.

Berdasarkan guideline yang dikeluarkan oleh Royal College of Obstetricians and Gynaecologists mengenai penanganan wanita dengan obesitas pada kehamilan, wanita pada usia reproduktif haruslah mendapatkan edukasi mengenai berat badan yang ideal sebelum hamil dan hal ini harus tetap dimonitori sampai pada 
masa kehamilan. Selain itu guideline tersebut juga menyatakan bahwa wanita dengan IMT $\geq 30 \mathrm{~kg} / \mathrm{m}^{2}$ (obes) atau dengan status gizi overweight sebelum hamil, haruslah mendapatkan edukasi mengenai informasi risiko obesitas terhadap kehamilan baik bagi janin maupun ibu sendiri. ${ }^{18}$

Davies et al. $^{19}$ juga mengeluarkan sebuah clinical practice guideline mengenai obesitas pada kehamilan dan merekomendasikan bahwa seorang wanita yang berencana untuk hamil harus menurunkan berat badannya sehingga IMTnya $<30 \mathrm{~kg} / \mathrm{m}^{2}$ atau dengan IMT ideal $<25 \mathrm{~kg} / \mathrm{m}^{2}$ sebelum memasuki masa kehamilan. Guideline tersebut juga menegaskan bahwa wanita hamil dengan status gizi obes haruslah mendapatkan konseling mengenai peningkatan berat badan yang sesuai, nutrisi, dan pilihan makanan selama kehamilan.

Berdasarkan dari kedua guideline tersebut dapat disimpulkan bahwa wanita hamil dengan obesitas yang menjalani persalinan di Prof. Dr. R. D. Kandou Manado masih kurang mendapatkan konseling prekonsepsi mengenai gizi sehingga prevalensi wanita hamil dengan obesitas masih tinggi di Manado.

Committe Opinion yang dikeluarkan oleh ACOG mengenai obesitas pada kehamilan menjelaskan bahwa wanita obes memiliki peningkatan risiko terjadinya komplikasi dalam kehamilan dan salah satunya adalah persalinan dengan seksio sesarea. ${ }^{2}$ Jika dilihat pada Tabel 2, dari total 926 wanita hamil dengan obesitas di akhir kehamilan terdapat 465 wanita hamil yang menjalani persalinan seksio sesarea dengan persentase 50,22\%.

Peningkatan tindakan seksio sesarea yang terjadi pada wanita hamil dengan obesitas berhubungan juga dengan komplikasi-komplikasi yang dimiliki selama kehamilan. Pada wanita hamil dengan obesitas cenderung memiliki komplikasi seperti preeklampsi, eklampsi, gawat janin, dan sebagainya yang merupakan salah satu alasan untuk menjalani persalinan seksio sesarea. ${ }^{9}$
Berdasarkan umur, pada hasil penelitian didapatkan bahwa wanita hamil dengan obesitas di akhir kehamilan paling banyak termasuk di kelompok umur 20 sampai 30 tahun. Hal ini sesuai dengan rekomendasi yang ada, bahwa umur 20 sampai 30 tahun merupakan kelompok umur reproduktif. Dari data hasil yang ada juga menjelaskan bahwa semakin meningkatnya usia, semakin besar pula prevalensi persalinan seksio sesarea dibandingkan dengan pervaginam. Hal ini disebabkan karena usia >35 tahun merupakan kelompok usia high risk pregnancy sehingga membutuhkan lebih banyak perhatian selama kehamilan. ${ }^{20}$

Pada Tabel 4, kita dapat melihat bahwa wanita hamil dengan obesitas paling banyak memiliki IMT 30 sampai 34,99 $\mathrm{kg} / \mathrm{m}^{2}$ atau obes I. Namun, terlihat pula bahwa semakin tinggi IMT maka semakin besar persentase untuk menjalani persalinan seksio sesarea. Hal ini sesuai dengan penelitian yang dilakukan oleh AlKubaisy et al. ${ }^{6}$ bahwa terdapat hubungan yang signifikan antara IMT dengan persalinan seksio sesarea. Dimana semakin tinggi IMT seseorang maka kejadian seksio sesarea semakin meningkat.

Penelitian yang serupa juga dilakukan oleh Scott-Pillai et al. ${ }^{17}$ yang mendapatkan hasil bahwa pada wanita hamil dengan status gizi obes III memiliki risiko lebih tinggi untuk menjalani persalinan seksio sesarea. Peningkatan risiko persalinan seksio sesarea ini termasuk dalam seksio sesarea emergensi dan elektif.

Semakin tinggi IMT seorang wanita hamil maka semakin tinggi pula risiko untuk menjalani persalinan seksio sesarea. Peningkatan IMT ini sejalan dengan peningkatan berat badan seorang wanita hamil. Pada tabel 5, terlihat bahwa semakin tinggi berat badan wanita hamil, khususnya kelompok berat badan di atas $85 \mathrm{~kg}$, maka semakin tinggi risiko untuk menjalani persalinan seksio sesarea. Hal ini disebabkan karena berat badan lebih dari $85 \mathrm{~kg}$ termasuk dalam kriteria kehamilan berisiko tinggi yang dievaluasi berdasarkan faktor sosial. ${ }^{21}$ Wanita hamil dengan berat 
badan lebih dari $85 \mathrm{~kg}$ lebih berisiko untuk mengalami berbagai komplikasi dalam kehamilan seperti hipertensi pada kehamilan dan diabetes gestasional sehingga menyebabkan peningkatan risiko untuk menjalani persalinan seksio sesarea. $^{22}$

Tabel 6 menampilkan perbandingan setiap jenis persalinan dengan jumlah paritas pada wanita hamil dengan obesitas pada akhir kehamilan menjelaskan bahwa tidak ada perbedaan yang signifikan antara persalinan seksio sesarea dan pervaginam terhadap jumlah paritas. Namun, dari data tersebut dapat disimpulkan bahwa wanita hamil dengan obesitas lebih banyak multipara dibandingkan primipara.

Penelitian yang dilakukan oleh Feresu et al. ${ }^{23}$ mendapatkan bahwa wanita hamil dengan obesitas lebih banyak multipara. Hal ini disebabkan karena peningkatan asupan makanan, penuruan aktivitas fisik, dan perubahan persisten fungsi endokrin akibat dari kehamilan yang berulang.

Limitasi penelitian ini ialah antara lain:

1. Data pasien dalam rekam medik banyak yang tidak lengkap khususnya data berat badan dan tinggi badan yang menentukan status gizi pasien.

2. Pada penelitian ini hanya dipakai status gizi wanita hamil pada akhir kehamilan berupa data tinggi badan dan berat badan untuk mengetahui IMT pada akhir kehamilan. Pada penelitianpenelitian sebelumnya, seharusnya digunakan pengukuran IMT pada awal kehamilan.

3. Kriteria inklusi dan eksklusi yang digunakan dalam penelitian masih sedikit sehingga hasil yang didapatkan belum terlalu terpusat pada obesitas karena masih melibatkan beberapa komplikasi dalam kehamilan.

\section{SIMPULAN}

Semakin meningkat IMT, berat badan, dan usia wanita hamil maka semakin tinggi risiko untuk menjalani persalinan seksio sesarea dibandingkan persalinan pervaginam.

\section{DAFTAR PUSTAKA}

1. World Health Organization. Obesity and overweight. 2015 [diakses 17 September 2015]. Tersedia di: http://www.who.int/mediacentre/facts heets/fs311/en/index.html

2. Obesity in pregnancy. Committee Opinion No.549. American College of Obstetricians and Gynecologist. Obstet Gynecol 2013;121:213-7.

3. Badan Penelitian dan Pengembangan Kesehatan Kementerian Kesehatan RI. Riset kesehatan dasar 2013. [diakses 17 September 2015]. Tersedia di: http://www.depkes.go.id/resources/do wnload/general/Hasil\%20Riskesdas\% 202013.pdf.

4. Pettigrew R, Hamilton-Fairley D. Obesity and female reproductive function. British Medical Bulletin. 1997;53(2):341-358.

5. Jungheim ES, Travieso JL, Hopeman MM. Weighing the impact of obesity on female reproductive function and fertility. Nutrition Review. 2013;71:3-8.

6. Al-Kubaisy W, Al-Rubaey M, Al-Naggar RA, Karim B, Noor NAM. Maternal obesity and its relation with the cesarean section: a hospital based cross sectional study in Iraq. BMC Pregnancy\&Childbirth. 2014;14:235.

7. Homer CSE, Kurinczuk JJ, Spark P, Brocklehurst P, Knight M. Planned vaginal delivery or planned caesarean delivery in women with extreme obesity. BJOG. 2011;118:480-7.

8. Carnero AM, Mejia CR, Garcia PJ. Rate of gestational weight gain, prepregnancy body mass index and preterm birth subtypes: a retrospective cohort study from Peru. BJOG. 2012;119:924-35.

9. Oteng-Ntim E, Varma R, Croker H, Poston L, Doyle P. Lifestyle interventions for overweight and obese pregnant woman to improve pregnancy outcome: systematic review and meta-analysis. BMC Medicine. 2012;10(47):1-15.

10.Aghdash SA, Ghojazadeh M, Dehdilani N, Mohammadi M, Abad RAA. Prevalence and causes of cesarean section in Iran: systematic review and 
meta-analysis. Iranian J Publ Health. 2014;43:545-55.

11.Feng XL, Wang Y, An L, Ronsmans C. Cesarean section in the people's Republic of China: current perspectives. International Journal of Woman's Health. 2014;6:54-79.

12.World Health Organization. WHO statement on caesarean section rates. 2015 [diakses 3 Oktober 2015]. Tersedia di: http: //apps.who.int/iris/bitstream/10665/16 1442/1/WHO_RHR_15.02_eng.pdf

13. Essex HN, Green J, Baston H, Pickett KE. Which women are at an increased risk of a caesarean section or an instrumental vaginal birth in the UK: an exploration within the millennium cohort study. BJOG. 2013;120:732-43.

14.Poobalan AS, Aucott LS, Gurung T, Smith WCS, Bhattacharya S. Obesity as an independent risk factor for elective and emergency caesarean delivery in nulliparaous womensystematic review and meta-analysis of cohort studies. Obesity reviews. 2009;10:28-35.

15.Liu L, Hong Z, Zhang L. Association of prepregnancy body mass index and gestational weight gain with pregnancy outcomes in nulliparaous women delivering single live babies. Scientific Reports. 2015;5:12863.

16.Girsen AI, Osmundson SS, Naqvi M, Garabedian MJ, Lyell DJ. Body mass index and operative times at cesarean delivery. Obstet Gynecol.
2014;124:684-9.

17.Scott-Pillai R, Spence D, Cardwell CR, Hunter A, Holmes VA. The impact of body mass index on maternal and neonatal outcomes: a retrospective study in a UK obstetric population, 2004-2011. BJOG. 2013;120:932-9.

18. Royal College of Obstetricians and Gynaecologists. Management of women with obesity in pregnancy. 2010 [diakses 25 Desember 2015]. Tersedia di: http://www.rcog.org.uk/globalassets/d ocuments/guidelines/cmacercogjointg uidelinemanagementwomanobesitypr egnancya.pdf

19.Davies GAL, Maxwell C, McLeod L. Obesity in pregnancy - SOGC clinical practice guideline. JOGC. 2010;239:165-73.

20.WebMD. Health and pregnancy. 2014 [diakses 25 Desember 2015]. Tersedia di: http://www.webmd.com/baby/guide/h igh-risk-pregnancy-overview

21. Yelikar K. Practical cases in obstetrics \& gynecology. Edisi 2. Nepal: Jaypee Brothers Medical Publishers; 2015.

22.Ramarajan A. Severe acute maternal morbidity. Nepal: Jaypee Brothers Medical Publishers; 2011.

23.Feresu SA, Wang $Y$, Dickinson S. Relationship between maternal obesity and prenatal, metabolic syndrome, obestetrical and perinatal complications of pregnancy in Indiana, 2008-2010. BMC Pregnancy and Childbirth. 2015;15:266. 